\title{
Vientos y latidos del pueblo Estudio acerca de las bandas de músicos del Bajo Piura
}

\author{
Virginia Yep \\ (Escuela Estatal de Música Paul-Hindemit, Berlín, Alemania)
}

Recibido: $12 / 2 / 2015$

Aprobado: 23/3/2015

Resumen. Las bandas de músicos son conformaciones instrumentales de vientos de metal y percusión, que están presentes en las actividades oficiales y religiosas de los pueblos en el Perú y también en muchas otras partes del mundo. En el Bajo Piura, zona yunga situada al norte del Perú, las bandas no solo cumplen un rol estructural en las fiestas patronales, sino que son consideradas "la música más típica" de la zona. El análisis nos da las claves para comprender este fenómeno musical.

Palabras clave: etnomusicología / bandas / Bajo Piura / Semana Santa / tondero

\section{Winds and Beats of the People. A Study of Marching Music Bands in Bajo Piura}

Summary. Marching music bands are ensembles of metal winds and percussion, present in official and religious activities of different peoples in Peru as well as in many other parts of the world. In Bajo Piura, in the yunga area located in northern of Peru, the bands do not only play a structural role in the festivities, but are considered "the most typical music" of the area. This analysis helps understand these musical phenomena.

Key words: ethnomusicology / marching music bands / Bajo Piura / Holy Week / tondero 


\section{Introducción}


n el paisaje desértico y de fértiles valles que caracteriza a una parte de la antigua zona tallán llamada Bajo Piura, son las fiestas populares las que mantienen el orden social en la vida del campesino. La intensiva práctica religiosa en estas festividades, generalmente con motivo de una fecha cristiana o en honor a un santo patrón, genera un tipo de práctica instrumental, que en la zona se conoce como "la música más típica": la banda.

Catacaos es un distrito de la provincia de Piura, departamento del mismo nombre, ubicado precisamente en la zona denominada Bajo Piura, donde la Semana Santa es la fiesta popular religiosa más importante del año. Todo un aparato organizativo y un sistema tradicional de "cargos" son necesarios para su realización, donde la banda de músicos desempeña un rol fundamental como elemento integrador y articulador del lenguaje ritual; con base en su función dentro de la fiesta, dicha banda ha desarrollado un lenguaje musical propio, cuyo análisis fue uno de los objetivos principales de mi tesis doctoral ${ }^{1}$.
La inexistencia de estudios musicales en esta región del Perú y la escasez de trabajos de análisis de esta práctica instrumental, en general, dentro de la literatura especializada, a pesar de la importancia de este tipo de ensambles en la vida civil de los pueblos y de las ciudades y en el aprendizaje de la música, me llevaron a ocuparme de este tema. Mi cuestionamiento central parte de la pregunta ¿cuáles son los elementos musicales que hacen que cualquiera que sea el género musical que la banda interprete -valse, polca, marinera, etc.- sea clasificado en versión de la banda, ya no de los géneros en mención, sino bajo el término de "música de banda", o simplemente como "banda"? La identificación de un estilo de banda en comparación con el estilo norteño en la música criolla, el análisis comparativo de las dos variantes (bandas y criollos) del tondero, danza típica de Piura (capítulos 2 y 3 de mi tesis) y el análisis de la marcha, género exclusivo de la banda, sientan las bases para la definición del arreglo musical como responsable del estilo de banda y de su continuidad (capítulos 5 y 6 de mi tesis). Con el reconocimiento, definición y análisis de

1 En el año 2000 presenté la tesis doctoral “Die bandas, eine Instrumentalpraxis und ihre deutung für das Musikleben in Bajo Piura, Nordperu" ("Las bandas, una práctica instrumental y su significado para la vida musical del Bajo Piura, norte del Perú") a la Facultad de Musicología Comparada de la Freie Universität Berlin, Alemania. El original en alemán se publicó en 2001, en http://www.diss.fu-berlin.de/diss/receive/FUDISS_thesis_000000000557 de la Biblioteca Universitaria y en 2008 en Akademikerverlag, Saarbrücken. 
los principios y técnicas del arreglo y de los métodos para ponerlos en la práctica queda respondida la pregunta central.

"La inspiración viene de Dios, por eso yo compongo cada año una nueva marcha para la Semana Santa...", me dijo una vez don Eucarpio Oliva, entonces director de la "Banda Santa Cecilia" de Catacaos, cuando realizaba el trabajo de campo para mi tesis; sí, esas bandas de vientos de madera y de metal, con "bombos y platillos", infaltables en las procesiones religiosas y en las plazas de los pueblos los domingos, y que se formaron, principalmente, para subrayar, ensalzar y dar máxima expresión a la devoción religiosa durante la Semana Santa en esa zona. Después de casi veinte años de esta conversación, ya don Eucarpio (1918-1997) partió de este mundo, y mi trabajo ha ganado un carácter histórico; sin embargo, el análisis musicológico continúa siendo válido, más allá del tiempo y del espacio, porque las bandas en el Bajo Piura siguen siendo los vientos y los latidos del pueblo.

"La banda es la música más típica, aquí, en el Bajo Piura", según el compositor cataquense Feliciano Chero, quien no estaba solo en su opinión, porque esta frase la escucharía cual estribillo, durante mis repetidas estadías en el Bajo Piura; entonces, banda es si- nónimo de música, pero además es "la más típica", ¿por qué?, ¿qué es lo especial en estas bandas? Esta interrogante será el hilo conductor de este artículo.

\section{Religiosidad, fiesta y banda}

Ya la leyenda de los orígenes de la cultura tallán y el desarrollo histórico del Bajo Piura (véase Yep, 2008, pp. 18-31) nos revelan la fuerte religiosidad de los habitantes de esta zona, canalizada a través de un trabajo grupal organizado. La alegría de haber superado las frecuentes catástrofes naturales, y recuperado las pérdidas, encuentra su expresión de gratitud en la fiesta patronal, que es el espacio donde la organización religiosa -cofradía, sociedad o hermandad- $\mathrm{y}$ sus representantes electos para la fiesta -mayordomos o alfereces- pueden mostrarse ante la colectividad y ganar con ello prestigio social ${ }^{2}$.

A lo largo del tiempo, aumentó el número de fiestas y con ello también el de las bandas, que se integraron al sistema del orden social y religioso, confirmándolo. Bajo estas condiciones histórico-sociales, las bandas son el elemento indispensable para la articulación e interacción de los participantes en la fiesta patronal, sobre esta afirmación volveré más adelante. Me decían los paisanos en Catacaos que

2 Tema analizado profundamente por Manuel Marzal desde el punto de vista de la religión comparada, en su libro El sistema religioso del campesino bajopiurano (Piura, 1983). 
la banda "nos conduce a los creyentes a sentirnos más cerca de Dios" durante la procesión, es decir, en un plano colectivo; tal como don Eucarpio recibiría, según él, la inspiración para sus marchas directamente de Dios, en un nivel individual.

Como en el Bajo Piura "la banda es la música...", el sonido de la banda muestra una estética propia, y además apela a diversas asociaciones individuales y colectivas que tienen que ver con la tradición oral, en forma de recuerdos y narraciones en torno a las fiestas pasadas y a los favores, promesas y milagros de las imágenes de los santos. En este proceso de comunicación, los actores (el compositor, el arreglista, la banda y los oyentes), los factores (las partituras, la ocasión, el espacio) y el lenguaje no verbal (movimiento, gesticulación, etc.), además de otros elementos extramusicales, que influyen en el toque de la banda, determinan el producto musical durante la procesión. Todo esto hace que se produzca una fuerte identificación de los bajopiuranos con sus fiestas, y en consecuencia, con la banda.

La banda es "el alma de la fiesta" y solo está presente durante las festividades, que rompen con la rutina diaria, es siempre representativa y su naturaleza implica tocar al aire libre. Su interacción con el oyente depende de su performance; cuando la banda toca en forma estática, en los actos oficiales o en retretas en la plaza, la gente la contempla, existe una distancia entre esta y los oyentes, y los músicos se concentran solo en tocar; en cambio, cuando la banda se desplaza, el toque regular de la percusión en base a fórmulas rítmicas fijas propias de la marcha (véase Yep, 2008, pp. 128-129), invitará a caminar con la banda. No debemos olvidar que la procesión transcurre en silencio y solo la música ocupa el espacio acústico, con lo que se confirma la función integral de la banda en el ritual religioso. En todo caso, la percusión tiene por función llamar la atención de los oyentes y convocarlos a participar contemplando la acción, marchando o, incluso, bailando al son de la banda.

La combinación de sonidos, de palabras, del movimiento corporal, del toque instrumental y del desplazamiento están en constante interacción en el ritual religioso: si bien la función principal de la banda en este contexto es acompañar y marcar musicalmente los momentos del ritual festivo, los niveles se entremezclan; no es raro ver que alguno de los músicos de la banda deje de tocar para hacer una ofrenda o una promesa a la imagen.

\section{“La banda es la música...”}

Cuando hay fiesta en el Bajo Piura, suena la banda y la gente identifica inmediatamente lo que está pasando, es decir, la acción, el estadio de la fiesta: si suena un "alba" son las siete de la mañana y seguidamente habrá retreta en la Plaza de Armas; si se oye un "al- 
bazo" o tiro, significa que el desayuno oficial ya terminó y la banda seguirá tocando en la plaza; si a mediodía la banda toca una "marcha regular" (de paso regular, andante), saben todos que se dirige a la casa de alguna autoridad del grupo religioso a almorzar, y si desde esa casa se oyen tonderos y marineras, es que están esperando el siguiente plato. Si en la tarde, la banda toca una marcha regular, es que acompaña a los principales a trasladar las imágenes para la procesión. Si es víspera, la banda tocará en la noche para los fuegos artificiales. Cuando se escucha el "miserere", todos saben que están sacando las imágenes de la Catedral para empezar la procesión. $\mathrm{Si}$ tocan una "marcha meditación" (procesional, de paso lento) la procesión ha empezado, y si en eso se escucha el golpe de una piedra contra el anda, la música se detiene y con ello también la procesión, para dar paso a un rezo, adoración, ofrenda, etc. En el Bajo Piura la gente maneja estos códigos, identificándose con los vientos y los latidos de la banda.

El hecho de que la banda marque los momentos de la fiesta, y que por ello sea infaltable en el ritual festivo, ayuda a comprender por qué "la banda es la música". Sin embargo, para responder en términos musicológicos a la interrogante central es necesario conocer las características del sonido de la banda, para lo cual tuve que formular antes otra pregunta: ¿cuál es el instrumento en la banda que no puede faltar, porque sin él no sonaría a banda? Los músicos de Catacaos me respondieron cuasi al unísono: el bombo, es decir el corazón que late y mantiene viva a la banda. La combinación bombo-tarola-platillos, que los músicos llaman "batería", contribuye a que todo suene "a banda".

Aunque la banda se reconoce principalmente por su toque de percusión, también la "entonación" o afinación de los instrumentos de viento caracteriza su sonido; la "afinación impura" es el producto de la técnica instrumental, del estado de conservación del instrumento y de su matiz, y le da al todo musical un carácter "de pueblo", especial e inconfundible. Los clarinetes, trompetas y saxos de la banda tienen un timbre diferente a sus originales europeos. El clarinete, por ejemplo, tiene un sonido en la banda que se acerca al sonido del pincullo.

Ciertas formas de la tradición oral ejercen influencia en la interpretación de la banda; existe un sobreentendido en torno a la lectura musical, que al mismo tiempo la contradice y hace que la tradición oral se cruce con la escrita y derive en variaciones rítmicas en la voz melódica, sonidos cuya presencia se debe a la técnica del instrumento, diferencias en la afinación y matices, un curso propio de los bajos, fórmulas rítmicas en la percusión y, sobre todo, de confrontaciones polirrítmicas del compás de $3 / 4$ y 6/8 en el tondero, que no están anotadas. Este proceso está tan enraizado en el pensamiento 
musical, que ni los músicos mismos pueden diferenciar claramente en qué medida son fieles a la notación y qué tanto está sobreentendido.

El llamado "arreglo musical" define el estilo de la banda, porque la composición comienza con la idea musical de una melodía, que recibe una forma adecuada para la banda; en otras palabras: como la razón de ser de la banda es tocar en la procesión, todo lo que toca, suena más o menos a marcha. El arreglo ha sentado las bases que hacen que la música de banda sea estilísticamente lo que es, independientemente del género que se interprete. En el Bajo Piura, la idea de cómo debe sonar la música de banda según el estilo de esta tiene mayor peso que las diferencias entre un género musical y otro; acá se presenta un pensamiento, donde lo común tiene prioridad frente a lo separador; en este contexto existe una tendencia a la "abandización"

"La banda toca todo" me repetían los músicos, mientras don Eucarpio Oliva me contaba que su banda, a diferencia de otras, tiene su propio repertorio. Como la banda Santa Cecilia sintetiza la historia de las bandas en Catacaos, esta asume una especie de monopolio de la música para banda, habiendo heredado además todo el repertorio de las bandas antiguas de la zona. Para darnos una idea de este repertorio, mencionaré los géneros que dominaba José Emilio Ramírez (18851953), el compositor más prolífico de Catacaos, cuyas obras para banda aún están vigentes y comprenden música popular (yaravíes, huainos, marineras, tonderos, valses, polcas, pasacalles, pasodobles, one-steps, tangos, foxtrots, pasillos, festejos y hasta rancheras, boleros y guarachas), música militar (marchas), marchas fúnebres (pasodobles fúnebres, meditación), obras para órgano (vigilia, réquiem, misas de Gloria, libera me domini y responsorial), música clásica (fantasía incaica). El repertorio actual de la banda se diferencia del repertorio de la época de Ramírez en que en vez de interpretar música clásica ahora se tocan ritmos como la tecnocumbia, el reaguetton, la lambada, la macarena, el culebreo, así como música criolla (valses, polcas, marineras) y baladas, boleros, cumbias, huainos, es decir, la banda toca todo lo que el público quiera escuchar. La música religiosa ha perdurado, sin embargo, incólume a los cambios e influencias de la "moda"; la marcha queda como el género propio y exclusivo de la banda, mientras que el tondero, la danza tradicio-

3 El análisis del arreglo como recurso para definir los criterios del estilo ocupa el capítulo 6 de mi tesis. En el arreglo se encuentra toda la gramática que apoya al sonido de la banda, independientemente del género musical, y por ello es la clave principal para responder a la hipótesis general de mi trabajo. 
nal de la zona, toma una nueva forma en versión de la banda ${ }^{4}$.

\section{La marcha de la banda}

La celebración de la Semana Santa en Catacaos se origina en los tiempos coloniales (Cruz, 1982, p. 504), y aunque nadie recuerde la música que entonces la acompañaba, esta celebración ha contribuido al desarrollo de la música religiosa actual de la zona. "Desde mi niñez quise ser músico para tocar en la Semana Santa para el Santo Sepulcro", me decía don Feliciano Chero, quien aprendió de su padre. Si la primera motivación de los músicos fue la de mostrar su religiosidad a través de la música y de la banda, la marcha es el mejor canal para expresarla. Religiosidad, fiesta, banda y marcha están encadenadas entre sí, en tanto que el primer factor encuentra su expresión en los otros. Como la música es el elemento que articula todo el ritual festivo, la cadena de asociaciones tiene su efecto no solo en los músicos, sino en todos los participantes de la procesión. Banda y marcha forman una unidad y son imprescindibles en el contexto del evento religioso; a esto se le suman factores externos y no-musicales, matices e instrumentación. Hofer confirma la dependencia mutua entre la banda y la marcha (militar) y las consecuencias y efectos acústicos:

También es la variación de los matices y del carácter de los sonidos, parte de la historia de las marchas militares. Si se quiere resumir la historia de la marcha como forma de composición propia, hay que ocuparse en especial del instrumentario de las bandas militares, porque justamente son sus matices los que impregnan el carácter de la marcha militar (Hofer, 1988, p. 8).

En la práctica, la marcha está pensada en primera línea para caminar en grupo. La procesión tiene dos tipos de caminos programados, que la marcha acompaña: en círculo, en donde la partida y la llegada son el mismo punto y el centro de la atención está en el paso; y el camino con una meta determinada, donde la llegada a la meta está en primer plano. A su vez, la marcha cumple principalmente dos funciones dentro de la fiesta:

- La representativa, que se da cuando algún miembro de la organización (hermandad religiosa, tropa militar, etc.), es escoltado desde su casa por la banda y va marchando hacia la iglesia al compás de una marcha regular, mostrando así al resto de la comunidad que ha tomado parte en la financiación de la fiesta. En este

4 El análisis comparativo del tondero en versión de los criollos y en versión de la banda se encuentra en el capítulo 4 de mi trabajo. El análisis de la marcha es el tema del capítulo 5. 
caso, la marcha no invita a la participación sino a la contemplación.

- La de acompañamiento está en relación con la creencia religiosa, cuyos antecedentes son una motivación personal (por ejemplo, una promesa hecha a un santo), o una motivación social (por ejemplo, las familias van a la procesión para encontrarse con conocidos). Se acompaña a una imagen durante la procesión (marcha meditación) o un sepelio hacia el cementerio (marcha fúnebre); esta función está abierta a todos, quien así lo desee puede caminar al compás de la marcha y acompañar.

Por otro lado, se observa algo en torno a las marchas: si bien son el género exclusivo de la banda, no existen grabaciones comerciales de ellas, porque son el producto sobreentendido de las bandas y pertenecen a la procesión y a la vida pública de la comunidad, lo cual confirma su función integral y su significado en el contexto religioso. De la misma manera en que las marchas para las procesiones de Viernes Santo y Domingo de Resurrección eran compuestas entonces por don Eucarpio Oliva, por encargo de una organización religiosa, toda persona, asociación o grupo religioso puede encargar la composición de una marcha y contratar a la banda; efectivamente, esto sucede en la práctica, pues más de un anciano cataquense me confesó que tenía un dinerito ahorrado "porque cuando me muera, quiero que me entierren con banda".

\section{“Hacer la música más bonita”}

La banda es una conformación instrumental que en el Bajo Piura es entendida como la música en sí, porque con su desarrollo y expansión, gracias a las fiestas patronales, ha ganado espacio ante otro tipo de manifestaciones musicales, cada vez menos frecuentes ${ }^{5}$, quedando prácticamente como única representante de la música en la zona. La gente gusta de la banda, porque es representativa y religiosa, observemos que la gran mayoría de las bandas llevan el nombre de un santo y de un lugar (por ejemplo, la banda Santa Cecilia de Catacaos), lo cual produce un fuerte efecto de totalización, identificación y de pertenencia de la gente con su banda. Además, gracias a ciertas familias y personalidades con generaciones de tradición musical (Taboada, Chero, Oliva, Purizaca, Mena, Dedios) que en el Bajo Piura asumen los contratos para las bandas, se ha creado un vasto repertorio de marchas, que se toca en todo el Perú, y que es reconocido como originario del Bajo Piura.

5 Antiguamente existían el conjunto arpa-cantor-golpeador (este último percutía en la caja de resonancia del arpa), el cajero (tocador de flauta de una sola mano y tamborcillo), los cumananeros, etc. 
La banda es la música porque su estilo propio, rígido y con pocas variaciones, la hacen única e inconfundible. Según el saxofonista Augusto Mena, el arreglo musical se define como "hacer la música más bonita", afirmación que subraya el gusto por el estilo de la banda; el análisis del arreglo, bajo un punto de vista etnomusicológico, es el objeto de estudio de mi tesis doctoral, que en este artículo no ha sido expuesto en toda su extensión y profundidad, por tratarse de una argumentación en términos musicales. Por último, "la banda es la música más típica, aquí, en el Bajo Piura", porque los paisanos así lo quieren, lo entienden y lo sienten.

A lo largo de los años que me dediqué a investigar y analizar el fenómeno de las bandas, pude comprobar que estas conformaciones instrumentales han sido muy poco estudiadas, a pesar de su frecuencia, su importancia para el aprendizaje musical y su poder de convocatoria en pueblos recónditos, no solo en el Perú sino en todas partes. Por ejemplo, también en el contexto europeo, las bandas dominan la vida musical de los pueblos de España, Portugal, sur de Alemania, Suiza y del Tirol, motivando a la gente joven a hacer música; a pesar de este poder, no se les menciona en los libros de historia de la música, y apenas en los diccionarios y enciclopedias especializadas (Suppan, 1984, pp. 497-510), tal vez porque no son lo suficientemente "clásicas" para la musicología, ni lo suficientemente "exóticas" para la etnomusicología.
Por ello, mi estudio busca reivindicar a las bandas, con el fin de que sean tomadas en serio y ocupen un lugar al margen de los prejuicios en la historia de la música. Y es que en el Bajo Piura, las bandas son los vientos y los latidos del pueblo, y ofrecen al investigador un vasto tema para futuros estudios en distintas disciplinas.

\section{Referencias}

Cruz Villegas, J. (1982). Catac Ccaos. Piura: Cipca.

Franco, E. (1981). Grupo cataquense y ritual en la fiesta de Semana Santa. Lima: Pontificia Universidad Católica del Perú.

Hofer, A. (1988). Studien zur Geschichte des Militärmarsches. Tutzing: Verlag Hans Schneider.

Marzal, M. (1983). El sistema religioso del campesino bajopiurano. Piura: Cipca.

Suppan, W. (1984). Die Entwicklung der Literatur für Amateur - Blasorchester in Mitteleuropa seit 1950. En Fest-schrift für Ernst Klusen zum 75. Geburtstag. Bonn am Rhein: Verlag Peter Wegener.

Yep, V. (2002). Fiesta, música y banda. La Semana Santa en Catacaos (Perú). Latin American Music Review, 206-222.

Yep, V. (2008). Die Bandas, eine Instrumentalpraxis und ihre Bedeutung für das Musikleben in Bajo Piura, Nordperu. Saarbrücken: VDM. 